\title{
DISPERSIVE LIQUID-LIQUID MICROEXTRACTION BASED ON SOLIDIFICATION OF FLOATING ORGANIC DROP FOR SIMULTANEOUS SEPARATION/PRECONCENTRATION OF NICKEL, COBALT AND COPPER PRIOR TO DETERMINATION BY ELECTROTHERMAL ATOMIC ABSORPTION SPECTROMETRY
}

\author{
Mooud Amirkavei, Shayessteh Dadfarnia* and Ali Mohammad Haji Shabani \\ Department of Chemistry, Faculty of Science, Yazd University, Yazd, 89195-741, Iran
}

Recebido em 11/3/12; aceito em 18/7/12; publicado na web em 7/12/12

\begin{abstract}
A dispersive liquid-liquid microextraction based on solidification of floating organic drop for simultaneous extraction of trace amounts of nickel, cobalt and copper followed by their determination with electrothermal atomic absorption spectrometry was developed. $300 \mu \mathrm{L}$ of acetone and 1-undecanol was injected into an aqueous sample containing diethyldithiocarbamate complexes of metal ions. For a sample volume of $10 \mathrm{~mL}$, enrichment factors of 277, 270 and 300 and detection limits of 1.2, 1.1 and $1 \mathrm{ng} \mathrm{L}^{-1}$ for nickel, cobalt and copper were obtained, respectively. The method was applied to the extraction and determination of these metals in different water samples.
\end{abstract}

Keywords: liquid-liquid microextraction; electrothermal atomic absorption spectrometry; nickel, cobalt and copper determination.

\section{INTRODUCTION}

Cobalt is a naturally occurring element found in rocks, soil, water, plants, and animals. It is an essential micronutrient required for the growth of both plants and animals. Cobalt can be beneficial for humans because it is part of the Vitamin $\mathrm{B}_{12}$. However, exposure to a high level of cobalt is harmful and can result in lung and heart effects and dermatitis. ${ }^{1}$ Copper and nickel combined with other elements occur naturally in the earth's crust. Copper is an essential nutrient, while nickel has no known beneficial health effects. However, both metals may be harmful if ingested in excessive amounts. The main route of intake for these elements is from foods. Copper and nickel can be present in foods naturally, as a result of pollution, or from the storage and processing of foods. ${ }^{2}$ Studies for cobalt, nickel and copper determination in water and biological matrices are very important because it is a good tool for environmental and toxicological monitoring. ${ }^{3-5}$ In spite of great improvements in the sensitivity and selectivity of modern instruments such as inductively coupled plasma mass spectrometry (ICP-MS), inductively coupled plasma optical emission spectroscopy (ICP OES) and electrothermal atomic absorption spectrometry (ETAAS), difficulties remain in the analysis of trace amounts of metals because of their low abundance levels in samples and the high complexity of sample matrices. ${ }^{6,7}$ Thus, efficient preconcentration and separation steps prior to their measurement remain essential. Various techniques have been devised for simultaneous separation and preconcentration of metal ions including liquid-liquid extraction, ${ }^{8,9}$ solid-phase extraction (SPE), ${ }^{10-12}$ Hollow fiber liquid phase microextraction (HF-LPME),$^{13}$ solidified floating organic drop microextraction (SFODME) ${ }^{14}$ and dispersive liquid-liquid microextraction (DLLME). ${ }^{15,16}$ The main objective of a sample preparation step is to isolate and concentrate the analytes of interest from the matrix and provide a suitable sample extract for instrumental determination. Liquid-liquid extraction (LLE) is a versatile classical sample preparation technique prescribed in many standard analytical methods. However, conventional LLE uses large amounts of potentially toxic organic solvents which are often hazardous and expensive. LLE is also considered to be a time consuming, tedious, and multistage operation. ${ }^{17}$ Efforts to overcome these limitations have

*e-mail: sdadfarnia@yazduni.ac.ir led to the development of microextraction in analytical chemistry. ${ }^{18}$ Miniaturized LLE or liquid phase microextraction (LPME) was introduced in $1996^{18,19}$ allowing the emergence of a different mode of LPME. ${ }^{17,20}$ Among different liquid phase microextraction techniques, dispersive liquid-liquid microextraction based on solidification of floating organic drop has attracted much research attention. ${ }^{17,21-25}$ This is due to its advantages of simplicity, rapidity, low cost, simple apparatus and consumption of very small amounts of low toxic organic solvent. This technique is based on the principle of DLLME and SFODME. Thus, a mixture of extraction (with a density lower than water) and dispersive solvent is rapidly injected into the aqueous sample containing the analyte of interest; a cloudy solution is formed and equilibrium is reached quickly due to the large surface area between the extraction solvent and the aqueous sample. The mixture is then centrifuged and the droplet of organic phase is floated on the aqueous phase. The sample vial is then placed in an ice bath, the drop is solidified, then easily removed and allowed to melt for determination. The solvent used in DLLME-SFO is similar to the solvent used in SFODME, i.e. it must have a density lower than water and a melting point close to room temperature $\left(10-30^{\circ} \mathrm{C}\right)$. Furthermore, the toxicity of the solvent of DLLME-SFO is lower than that of DLLME and there is no need for specific glass tubes.

In this study, the possibility of simultaneous enrichment of metal ions by DLLME-SFO was considered. Sodium diethyldithiocarbamate (DDTC), the classical organic reagent was selected as the complexing agent and a DLLME-SFO method combined with graphite furnace atomic absorption spectrometry (GFAAS) was developed for separation, enrichment and determination of cobalt, nickel and copper in water samples. Factors affecting the extraction efficiency and determination of the mentioned metal ions were systematically investigated.

\section{EXPERIMENTAL}

\section{Reagents and chemicals}

All reagents used were at least of analytical reagent grade and purchased from the Merck Company (Darmstadt, Germany). Deionized water was used throughout this study. The standard stock solutions of nickel (II) (1000 $\left.\mathrm{mg} \mathrm{L}^{-1}\right)$, cobalt (II) (1000 mg L-1) and copper 
(II) $\left(1000 \mathrm{mg} \mathrm{L}^{-1}\right)$ were prepared by dissolving the proper amount of $\mathrm{Ni}\left(\mathrm{NO}_{3}\right)_{2} \cdot 6 \mathrm{H}_{2} \mathrm{O}$ (Merck), $\mathrm{CoCl}_{2}$ (Merck) and $\mathrm{Cu}\left(\mathrm{NO}_{3}\right)_{2} \cdot 6 \mathrm{H}_{2} \mathrm{O}$ (Merck) in $1 \%$ nitric acid solution. Standard solutions were prepared daily by appropriate dilution of stock solutions. 1-Undecanol was obtained from Merck (Darmstedt, Germany) and was used as the extracting solvent. Sodium chloride (Merck, Darmstadt, Germany) was of the highest purity available. A solution of Sodium diethyldithiocarbamate (DDTC, $0.1 \mathrm{~mol} \mathrm{~L}^{-1}$ ) was prepared by dissolving the proper amount of DDTC in water.

\section{Instrumentation}

A Varian Zeeman spectra atomic absorption spectrometer, model $220 Z$ was used for all metal measurements throughout this study. Varian spectra-AA hollow cathode lamps for $\mathrm{Ni}, \mathrm{Co}$ and $\mathrm{Cu}$ were used as light sources and operated at currents of 4, 7 and $4 \mathrm{~mA}$, a wavelength of 232.2, 342.5 and $327.4 \mathrm{~nm}$ with a spectra bandwidth of $0.2,0.2$ and $0.5 \mathrm{~nm}$, respectively, as recommended by the manufacturers. The furnace tube was a standard platform tube with a pyrolytic coating. The furnace programs were optimized and are given in Table 1. Peak height measurement was used for all quantifications. The $\mathrm{pH}$ measurements were carried out with a Metrohm $\mathrm{pH}$ meter (model 691, Switzerland) using a combined glass calomel electrode. A centrifuge (Hitachi, Universal 320, Tuttlingen, Germany) was used for centrifuging.

\section{Extraction procedure}

The ionic strength and $\mathrm{pH}$ of a standard or sample solution were adjusted to 0.01 (using $\mathrm{NaCl}$ ) and $\sim 7$ (using diluted nitric acid or ammonium hydroxide solution), respectively. Subsequently, $10 \mathrm{~mL}$ of solution containing no more than 1, 1.2 and 1.5 ng of copper, cobalt and nickel, respectively was placed into a $\sim 12 \mathrm{~mL}$ vial and $100 \mu \mathrm{L}$ of $1.3 \times 10^{-3} \mathrm{~mol} \mathrm{~L}^{-1}$ of DDTC solution as complexing agent was added. The metal ions in the aqueous phase were complexed with DDTC. A mixture of $100 \mu \mathrm{L} 1$-undecanol (as the extraction solvent) and $200 \mu \mathrm{L}$ acetone (as the dispersive solvent) was then rapidly injected into the aqueous sample. In this stage, a cloudy solution was formed in the vial which was stable for a long period and complexes were extracted into 1-undecanol within a few seconds. The mixture was then centrifuged at $2200 \mathrm{rpm}$ for $3 \mathrm{~min}$ and the dispersed droplets of extraction solvent were coagulated and floated on the top of the aqueous phase. The vial was transferred into a beaker containing crushed ice and the organic solvent containing the analyte complexes was solidified after 5 min. The solidified extract was then transferred into a conical vial where it melted immediately. Finally, for determination of each analyte, $10 \mu \mathrm{L}$ of the extract was manually injected into the graphite furnace atomic absorption spectrometer.

\section{RESULTS AND DISCUSSION}

Sodium diethyldithiocarbamate (DDTC) is a classical ligand that forms complexes with many metal ions including $\mathrm{Cu}^{2+}, \mathrm{Co}^{2+}$ and $\mathrm{Ni}^{2+}$, according to Equation 1:<smiles>[Y16][Y11]1=[SH]N(C(=S)N(CC)CC)S1</smiles>

DDTC is relatively soluble in water but its complexes have low solubility in aqueous phase. In the preliminary experiments, it was observed that the metal complexes of DDTC are soluble in 1-undecanol, hence DDTC was used for the separation and extraction of $\mathrm{Ni}, \mathrm{Co}$, and $\mathrm{Cu}$ by the DLLME-SFO method followed by their determination by GFAAS as a micro amount sample analysis technique.

In order to obtain a high enrichment factor, different parameters affecting the complex formation, extraction and analyte determination were optimized using the univariable approach.

\section{Optimization of furnace temperature program}

At the primary step of this analysis, it was demonstrated that the temperature program suggested by manufacturers would not be efficient in this method as the magnitude of background was high. In order to avoid the loss of the metal ions of interest and in order to eliminate the background signal during the analysis, the temperature of the ETAAS was optimized and results are provided in Table 1. Under these conditions, the background was low and the peaks had a normal shape. With regard to the boiling point of 1-undecanol $\left(243{ }^{\circ} \mathrm{C}\right)$, it was proven that a drying temperature of $270{ }^{\circ} \mathrm{C}$ with the hold time of $10 \mathrm{~s}$ is necessary for the evaporation of the solvent. The optimal pyrolysis temperature for these metals was $900{ }^{\circ} \mathrm{C}$ and the optimal atomization temperatures were, 2600,2500 and $2600{ }^{\circ} \mathrm{C}$ for $\mathrm{Cu}^{2+}, \mathrm{Co}^{2+}$ and $\mathrm{Ni}^{2+}$, respectively (Figure 1). Under these conditions no modifiers were required and the proper results were achieved.

Table 1. Temperature program of EtAAS for determination of analytes

\begin{tabular}{lccccc}
\hline \multirow{2}{*}{ Steps } & \multicolumn{3}{c}{ Temperature $\left({ }^{\circ} \mathrm{C}\right)$} & $\begin{array}{c}\text { Time } \\
(\mathrm{S})\end{array}$ & $\begin{array}{c}\text { Argon flow } \\
\text { rate } \\
\left(\mathrm{L} \mathrm{min}^{-1}\right)\end{array}$ \\
\hline 1 & $\mathrm{Ni}$ & $\mathrm{Co}$ & $\mathrm{Cu}$ & 5 & 3 \\
2 & 95 & 95 & 95 & 5 & 3 \\
3 & 120 & 120 & 120 & 40 & 3 \\
4 & 270 & 270 & 270 & 10 & 3 \\
5 & 800 & 800 & 800 & 10 & 0 \\
6 & 2600 & 2500 & 2600 & 3.1 & 3 \\
\hline
\end{tabular}

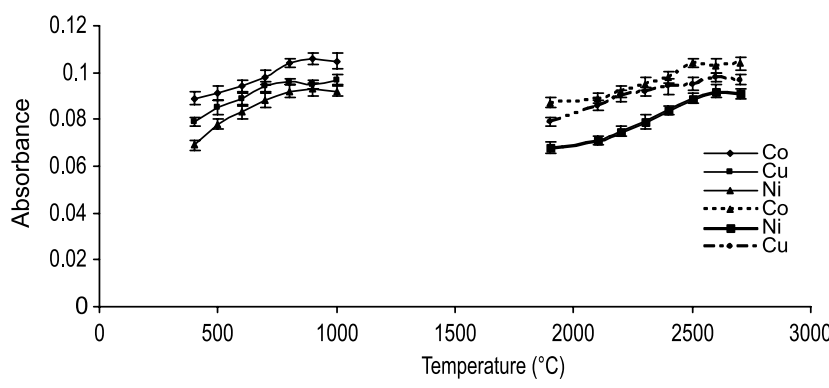

Figure 1. Effect of pyrolysis and atomization temperature on the absorption of $10 \mu \mathrm{g} \mathrm{L} \mathrm{L}^{-1}$ of $\mathrm{Ni}$, $\mathrm{Co}$ and $\mathrm{Cu}$

\section{Selection of nature of organic and dispersive solvent}

In the DLLME-SFO procedure, the selection of organic solvent has a significant effect on the recovery factors of the metal ion complexes. The extracting solvent must fulfill several requirements as follows: 1- It must be immiscible in the water and miscible with the disperser solvent. 2 - Its melting point should be near room temperature (10-30 $\left.{ }^{\circ} \mathrm{C}\right) .3$ - Its density must be less than water. 4 - The complexes should have high solubility in extracting solvent and the solvent must be compatible with the analytical technique of measurement. 5 -It must have low volatility in order to be stable during the extraction period.

Thus, several extraction solvents usually used in SFODME including 1-undecanol, 1-dodecanol, 1,10-dichlrodecane and n-hexadecane were investigated. Among these solvents, 1 -undecanol was selected as 
the extraction solvent since it afforded the best extraction efficiency. The extraction efficiency of 1-dodecanol was around $89 \%$ of 1-undecanol. However, n-hexadecane and 1,10-dichlrodecane were ruled out as n-hexadecane does not have sufficient solubility in usual dispersive solvents while 1,10-dichlrodecane produced high background during the analysis, interfering with the determination of the analytes.

The disperser solvent must be miscible with extraction solvent and water. Thus, in this experiment acetone, ethanol, methanol and acetonitrile were tested. With acetonitrile, emulsion was formed and separation of the two phases proved difficult. With acetone on the other hand, the cloud was very stable and recoveries higher than with either, ethanol or methanol. Thus, acetone was selected as the most suitable dispersive solvent due to its low toxicity, low cost and high analytical signals.

\section{Effects of volume of extraction and disperser solvent}

Demonstration of the preconcentration capability of the DLLMESFO system is an important aspect of the method development. An increase in the ratio of volume of aqueous phase to organic phase will increase the preconcentration factor, but it may reduce the extraction efficiency in a given extraction time. The influence of 1-undecanol volume $(20-160 \mu \mathrm{L})$ on extraction efficiency was investigated. Several experiments were performed using $200 \mu \mathrm{L}$ of acetone as disperser solvent and different volumes of 1-undecanol as the extraction solvent. The relative recoveries indicate that when the volume of 1-undecanol is varied in the range of $30-160 \mu \mathrm{L}$, extraction efficiency is maximal and constant. Therefore, a volume of $100 \mu \mathrm{L}$ of 1 -undecanol was used for optimization (for each extract, the determination of each analyte was repeated three times), whereas $30 \mu \mathrm{L}$ of 1 -undecanol was used when obtaining the performance data and analyzing the real sample

The effects of the volume of acetone as the dispersive solvent in the 50-400 $\mu \mathrm{L}$ range on the extraction efficiency of analytes were examined while the volume of 1-undecanol as the extraction solvent was fixed at $100 \mu \mathrm{L}$. The results showed that by increasing the volume of disperser solvent up to $200 \mu \mathrm{L}$, the absorbance of analytes increased and then leveled off up to a volume of $300 \mu \mathrm{L}$ of acetone. When the volume of acetone was low,1-undecanol was not completely dispersed and extraction efficiency was low. At a volume of acetone greater than $300 \mu \mathrm{L}$, the extraction efficiency was slightly decreased probably due to the increase in the solubility of the analytes in the aqueous phase containing a high percentage of acetone. Thus, $200 \mu \mathrm{L}$ of acetone was selected as the optimal volume of the dispersive solvent.

\section{Effect of sample pH}

The $\mathrm{pH}$ of the sample solution is one of the most important factors affecting the formation of the complexes and their subsequent extraction into organic phase. The effect of $\mathrm{pH}$ of solution on the extraction of DDTC complexes of copper, cobalt and nickel was studied by varying the $\mathrm{pH}$ within the range $0.5-11$. The $\mathrm{pH}$ was adjusted by either diluted nitric acid or ammonium hydroxide solution, while the other variables were kept constant. The results illustrated in Figure 2 demonstrate that at a $\mathrm{pH}>6$ the analytical signal is almost constant. The progressive decrease in extraction at $\mathrm{pH}<6$ might be due to the competition of the proton with the analytes for the reaction with DDTC. Therefore, a $\mathrm{pH} \sim 7$ was selected as the optimum $\mathrm{pH}$ for the subsequent work.

\section{Effect of DDTC concentration}

The efficiency of analyte extraction is dependent on the quantitative formation of the complex between the ligand and the analytes.

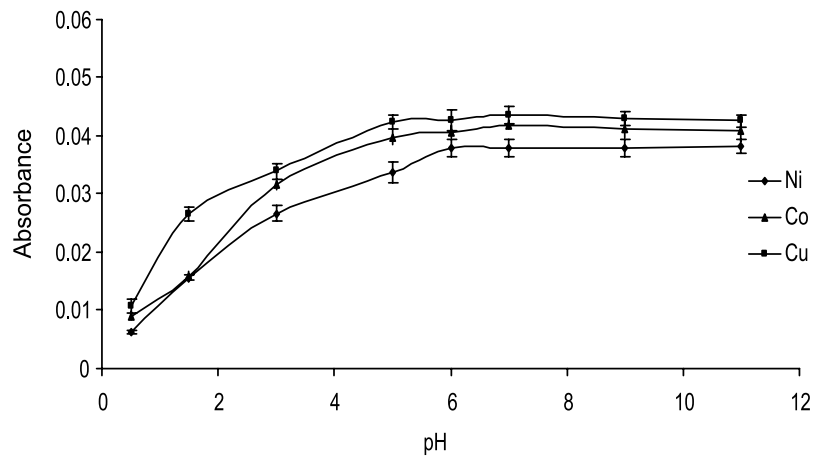

Figure 2. Effect of $p H$ on the extraction of analytes by DLLME-SFO. Extrac-

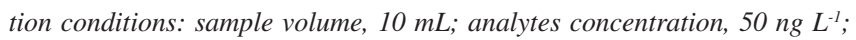
volume of organic phase, $100 \mu \mathrm{L}$; acetone volume, $200 \mu \mathrm{L} ;$ DDTC concentration $3 \times 10^{-7} \mathrm{~mol} \mathrm{~L}^{-1}$; salt concentration $5 \times 10^{-3} \mathrm{~mol} \mathrm{~L}^{-1}$

At constant aqueous phase $\mathrm{pH}$, up to a certain amount of ligand, formation of the complex and consequently the extraction efficiency, increases according to the increase in ligand concentration while extraction efficiency remains constant at higher concentrations of ligand. Thus, the effect of DDTC concentration on the extraction efficiency was evaluated by varying its concentration in the range of $1.6 \times 10^{-8}$ $3.4 \times 10^{-7} \mathrm{~mol} \mathrm{~L}^{-1}$. The analyte signals reached their maximum when the concentration of DDTC was $1.3 \times 10^{-7} \mathrm{~mol} \mathrm{~L}^{-1}$ and leveled off at higher concentrations (Figure 3 ). Therefore, a concentration of 1.3 $\times 10^{-7} \mathrm{~mol} \mathrm{~L}^{-1}$ of DDTC was selected as the optimum concentration for further studies.

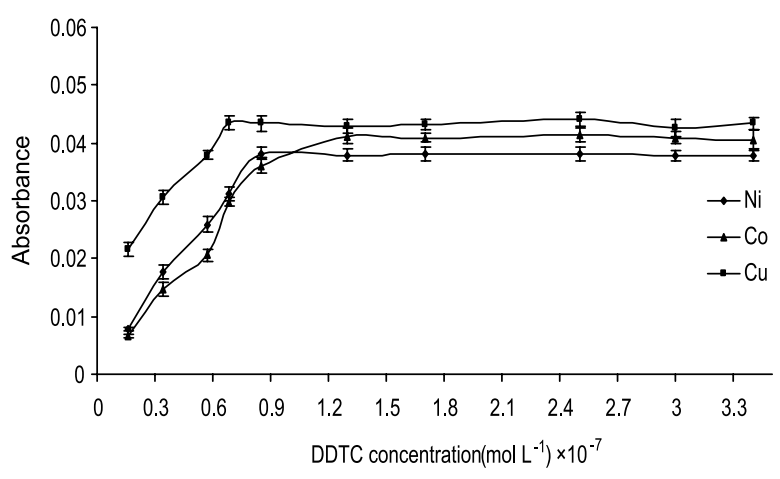

Figure 3. Effect of concentration of DDTC on the extraction of analytes by DLLME-SFO. Extraction condition: sample volume, $10 \mathrm{~mL}$; analytes concentration, $50 \mathrm{ng} \mathrm{L}^{-1}$; volume of organic phase, $100 \mu \mathrm{L}$; acetone volume, 200 $\mu L ; p H \sim 7$; salt concentration $5 \times 10^{-3} \mathrm{~mol} \mathrm{~L}^{-l}$

\section{Effect of salt}

To study the effect of salt addition on extraction efficiency, the concentration of $\mathrm{NaCl}$ was changed in the range $0.0-0.1 \mathrm{~mol} \mathrm{~L}^{-1}$ while other experimental parameters where kept constant. Addition of salt to the aqueous phase usually results in an improvement of extraction efficiency by the process of the salting-out effect. The results indicated a gradual increase in the analytical signals of the metal ions with increased $\mathrm{NaCl}$ concentrations up to $0.01 \mathrm{~mol} \mathrm{~L}^{-1}$ which then remained constant with further increases in the salt concentration. Thus, a concentration of $0.01 \mathrm{~mol} \mathrm{~L}^{-1}$ of $\mathrm{NaCl}$ was used for further studies.

\section{Effect of sample volume}

In order to explore the possibility of enriching low concentrations 
of the analytes from the large volume, the effect of sample volume on extraction of $0.5 \mathrm{ng}$ of analytes from different aqueous volumes (5-50 mL) at optimum conditions was examined using an appropriate size vial. The results presented in Figure 4 showed that extraction efficiencies were constant up to a volume of $40 \mathrm{~mL}$ and then decreased upon further increase in sample volume. However, as ETAAS has good sensitivity, a more convenient sample volume of $10 \mathrm{~mL}$ was used in further experiments. Based on the organic phase volume of $30 \mu \mathrm{L}$ and sample volume of $10 \mathrm{~mL}$, a preconcentration factor of 333 was determined. Extending the sample processing volume, however, improved method sensitivity. In the present study, the preconcentration factor can be extended by increasing the sample volume to $40 \mathrm{~mL}$.

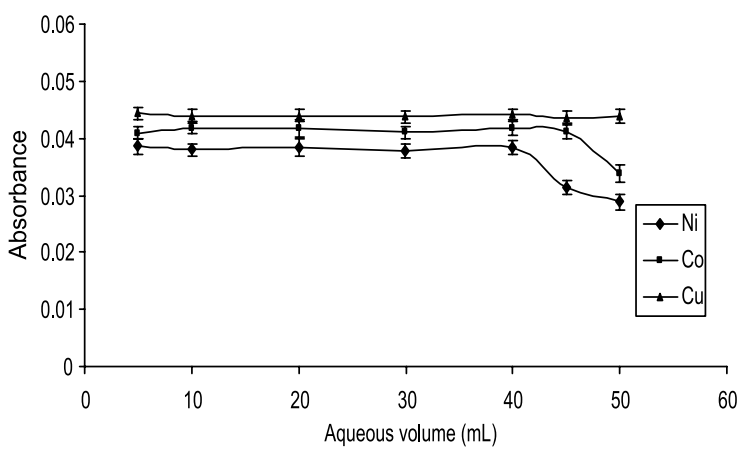

Figure 4. Effect of sample volume on extraction of analytes by DLLME-SFO.

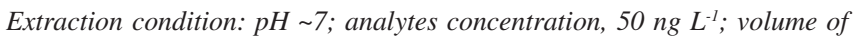
organic phase, $100 \mu \mathrm{L}$; acetone volume, $200 \mu \mathrm{L}$; DDTC concentration $3 \times$ $10^{-7} \mathrm{~mol} \mathrm{~L}^{-1}$; salt concentration $5 \times 10^{-3} \mathrm{~mol} \mathrm{L^{-1 }}$

\section{Effect of extraction time}

In DLLME-SFO, extraction time is defined as the time interval between the time of injection of the mixture of dispersive and extraction solvent and the time of centrifugation. The effects of the extraction time on the analytical signals were examined over the time range of 0-10 min under constant experimental conditions. The results showed that the extraction time had no significant impact on extraction efficiency. This can be explained on the bases that after the formation of a cloudy solution, the surface area between the extraction solvent and the aqueous phase is very large. The transition of the complex from aqueous phase to the extraction solvent and achievement of equilibrium is therefore fast. Thus, the most important advantage of the DLLME-SFO method is its time independency. In this method, the time-consuming steps are centrifuging of the sample solution and solidification of 1-undecanol, which together take about 8 min.

\section{Effect of diverse ions}

The effect of potential ions usually present in natural water on the preconcentration and determination of analytes was examined. For this purpose, a solution of $50 \mathrm{ng} \mathrm{L}^{-1}$ of the analytes containing various amounts of interfering ions was treated according to the optimized procedure. The tolerance limit of coexisting ions was defined as the largest amount producing a variation of less than 5\% in the recovery of analytes. The tolerance limits of diverse ions are given in Table 2. The results indicated that the presence of the ions at the mole ratio shown in Table 2 has no significant effect on the extraction of analytes.

\section{Figures of merit of the proposed method}

The performance characteristics of the method were obtained by processing $10 \mathrm{~mL}$ of standard solution of the analytes under the
Table 2. Tolerance limit of diverse ions on the quantitative recovery of analytes (analytes concentration $50 \mathrm{ng} \mathrm{L}^{-1}$ )

\begin{tabular}{cc}
\hline JIons & Mole ratio (Ion/analytes) \\
\hline $\mathrm{K}^{+}, \mathrm{Mg}^{2+}, \mathrm{Ca}^{2+}, \mathrm{Al}^{3+}, \mathrm{I}, \mathrm{F}^{-}, \mathrm{Br}^{-}, \mathrm{SO}_{4}^{2-}, \mathrm{CO}_{3}^{2-}$ & 1000 \\
$\mathrm{Hg}^{2+}, \mathrm{Zn}^{2+}, \mathrm{Fe}^{3+}, \mathrm{Pb}^{2+}$ & 750 \\
$\mathrm{Cd}^{2+}$ & 500 \\
\hline
\end{tabular}

optimized conditions. The calibration graphs exhibited linearity over the 10-120 $\mathrm{ng} \mathrm{L}^{-1}$ range for nickel, 10-100 $\mathrm{ng} \mathrm{L}^{-1}$ for cobalt and $7-150 \mathrm{ng} \mathrm{L}^{-1}$ for copper. The equations of the calibration curves and correlation coefficients for $\mathrm{Ni}^{2+}, \mathrm{Co}^{2+}$ and $\mathrm{Cu}^{2+}$ were: $\mathrm{A}=0.0025 \mathrm{C}+$ $0.004\left(\mathrm{R}^{2}=0.9997\right), \mathrm{A}=0.0027 \mathrm{C}+0.0061\left(\mathrm{R}^{2}=0.9998\right)$ and $\mathrm{A}=$ $0.003 \mathrm{C}-0.0029\left(\mathrm{R}^{2}=0.9993\right)$, respectively. The enhancement factors, defined as the ratio of the slope of calibration curves prepared from aqueous solutions submitted to the recommended procedure to that obtained without preconcentration, were found to be 277 for $\mathrm{Ni}^{2+}$, 270 for $\mathrm{Co}^{2+}$ and 300 for $\mathrm{Cu}^{2+}$.

The limits of detection, defined as $3 \mathrm{~S}_{\mathrm{b}} / \mathrm{m}$ (where $\mathrm{S}_{\mathrm{b}}$ is standard deviation of the blank and $\mathrm{m}$ is the slope of the calibration graph) were $1.2,1.1,1.0 \mathrm{ng} \mathrm{L}^{-1}$, limits of quantification, defined as $10 \mathrm{~S}_{\mathrm{b}} / \mathrm{m}$ were 3.9, 3.7, $3.4 \mathrm{ng} \mathrm{L}^{-1}$, and relative standard deviation (RSD) for 7 replicate measurements at $40 \mathrm{ng} \mathrm{L}^{-1}$, were $3.2 \%, 4.4 \%, 3.8 \%$ for $\mathrm{Ni}^{2+}, \mathrm{Co}^{2+}$ and for $\mathrm{Cu}^{2+}$, respectively.

\section{Application}

To examine the accuracy of the proposed procedure, the method was applied to the determination of analytes in tap water, well water, spring water, river water and sea water. The water samples were filtered through a $0.45 \mu \mathrm{m}$ pore-size Millipore membrane and were treated according to the recommended procedure. The accuracy of the method was verified by the analysis of the samples spiked with known amounts of the analytes. As demonstrated in Table 3, the recoveries of spiked samples were good (95.5-103.5\%). Thus, these results indicate that the matrices of tap, well, spring, river and sea have no significant effect on the DLLME-SFO-ETAAS method for the determination of the analytes.

Furthermore, in order to verify the accuracy of the proposed method, the procedure was used for the determination of $\mathrm{Co}, \mathrm{Ni}$ and $\mathrm{Cu}$ in certified sea water (NASS-1). The concentrations of cobalt, copper and nickel in the sample were found to be $4.1 \pm 0.4,98 \pm 5$ and $259 \pm 10 \mathrm{ng} \mathrm{L}^{-1}$, respectively, which at a $95 \%$ confidence limit, are in good agreement with the certified values $\left(\mathrm{ng} \mathrm{L}^{-1}\right)$ of $4 \pm 1$ for $\mathrm{Co}, 99 \pm 10$ for $\mathrm{Cu}$ and $257.0 \pm 27$ for $\mathrm{Ni}$. Thus, the method is reliable for determination of $\mathrm{Co}, \mathrm{Cu}$ and $\mathrm{Ni}$ in natural water samples.

\section{Comparison with other methods}

Separation and determination of analytes in water samples by the developed DLLME-SFO method was compared with that of other reported liquid microextraction methods and results shown in Table 4.With the exception of SFODME-GFAAS and IL-SDMELTEV-ICP-MS, the proposed DLLME-SFO method has a higher enrichment factor and consequently a lower detection limit. However, the extraction time of the proposed method is shorter than that of SFODME-GFAAS.

\section{CONCLUSIONS}

It has been demonstrated that the DLLME-SFO method can be used for simultaneous separation and enrichment of ultra-traces of 
Table 3. Determination of analytes in real water samples

\begin{tabular}{|c|c|c|c|c|c|c|c|c|c|}
\hline \multirow{2}{*}{ Sample } & \multicolumn{3}{|c|}{ Added (ng L ${ }^{-1}$ ) } & \multicolumn{3}{|c|}{ Found $^{\mathrm{a}}\left(\mathrm{ng} \mathrm{L}^{-1}\right)$} & \multicolumn{3}{|c|}{ Recovery (\%) } \\
\hline & $\mathrm{Ni}$ & $\mathrm{Co}$ & $\mathrm{Cu}$ & $\mathrm{Ni}$ & $\mathrm{Co}$ & $\mathrm{Cu}$ & $\mathrm{Ni}$ & $\mathrm{Co}$ & $\mathrm{Cu}$ \\
\hline \multirow[t]{2}{*}{ Tap water } & 0 & 0 & 0 & $88.9 \pm 2.4$ & $75.8 \pm 2.2$ & $79.9 \pm 2.6$ & - & - & - \\
\hline & 20 & 20 & 20 & $108.5 \pm 2.8$ & $95.1 \pm 1.6$ & $99.7 \pm 3.8$ & 98.0 & 96.5 & 99.0 \\
\hline \multirow[t]{2}{*}{ Well water } & 0 & 0 & 0 & $98.2 \pm 2.4$ & $83.8 \pm 2.3$ & $110.2 \pm 3.4$ & - & - & - \\
\hline & 20 & 20 & 20 & $117.9 \pm 2.7$ & $102.9 \pm 2.9$ & $129.9 \pm 3.4$ & 98.5 & 95.5 & 98.5 \\
\hline \multirow[t]{2}{*}{ Spring water } & 0 & 0 & 0 & $44.3 \pm 1.2$ & $56.1 \pm 2.3$ & $35.4 \pm 1.2$ & - & - & - \\
\hline & 20 & 20 & 20 & $64.4 \pm 1.7$ & $75.9 \pm 3.1$ & $54.7 \pm 1.3$ & 100.5 & 99.0 & 96.5 \\
\hline \multirow[t]{2}{*}{ River water* } & 0 & 0 & 0 & $154.9 \pm 5.2$ & $163.6 \pm 5.9$ & $147.2 \pm 6.3$ & - & - & - \\
\hline & 20 & 20 & 20 & $175.1 \pm 8.2$ & $183.4 \pm 7.3$ & $167.9 \pm 5.2$ & 101.0 & 99.0 & 103.5 \\
\hline \multirow[t]{2}{*}{ Sea water* } & 0 & 0 & 0 & $300.0 \pm 7.8$ & $254.4 \pm 6.8$ & $390.0 \pm 8.1$ & - & - & - \\
\hline & 20 & 20 & 20 & $319.6 \pm 7.1$ & $273.8 \pm 7.4$ & $409.1 \pm 9.2$ & 98.0 & 97.0 & 95.5 \\
\hline
\end{tabular}

${ }^{\mathrm{a}}$ Mean and standard deviation of three determinations. $* 4 \mathrm{~mL}$ of the sample was diluted to the $10 \mathrm{~mL}$.

Table 4. Comparison of enrichment, detection limit and sample volume of the proposed method with others reported microextraction methods

\begin{tabular}{|c|c|c|c|c|c|c|c|c|}
\hline \multirow{2}{*}{ Method } & \multicolumn{3}{|c|}{ Enrichment factor } & \multicolumn{3}{|c|}{ Detection limit $\left(n g \mathrm{~L}^{-1}\right)$} & \multirow{2}{*}{$\begin{array}{l}\text { Sample volume } \\
(\mathrm{mL})\end{array}$} & \multirow{2}{*}{ Refs. } \\
\hline & $\mathrm{Ni}$ & $\mathrm{Co}$ & $\mathrm{Cu}$ & $\mathrm{Ni}$ & Co & $\mathrm{Cu}$ & & \\
\hline CPE-ETAAS & 46 & 53 & 53 & 9 & 8 & 6 & 10 & 31 \\
\hline CPE-ETAAS & 27 & - & - & 120 & - & - & 10 & 30 \\
\hline SDME-LTEV-ICP-MS & - & 125.0 & - & - & $0.99\left(\mathrm{pg} \mathrm{L}^{-1}\right)$ & - & 1 & 26 \\
\hline HF-LPME-ETV-ICP-MS & - & - & 305.0 & - & - & 12.4 & 2.5 & 27 \\
\hline DLLME-FO-LADS & - & 165.0 & - & - & 200.0 & - & 10 & 16 \\
\hline DLLME-FAAS & - & - & 42.0 & - & - & 3000.0 & 5 & 28 \\
\hline IL-SDME-ETV-ICP-MS & - & 350.0 & - & - & 1.5 & - & 1.5 & 29 \\
\hline DLLME-ETAAS & 101.0 & 200.0 & - & 21.0 & 33.0 & - & 10 & 32 \\
\hline SFODME-ETAAS & 490.0 & 500.0 & - & 0.3 & 0.4 & - & 10 & 14 \\
\hline HF-LPME-ETAAS & 60.0 & - & - & 30.0 & - & - & 3 & 13 \\
\hline DLLME-SFO-ICP-OES & - & 76.0 & 93.0 & - & 200.0 & 200.0 & 20 & 24 \\
\hline DLLME-SFO-ETAAS & 277.0 & 270.0 & 300.0 & 1.2 & 1.1 & 1.1 & 10 & This work \\
\hline
\end{tabular}

cobalt, nickel and copper. Furthermore, the method permits effective separation and preconcentration of analytes and final determination by ETAAS in several categories of natural waters. The most important advantages of the method are very short extraction time, ease of operation, minimum consumption of low toxic organic solvent, and a high enrichment factor.

\section{REFERENCES}

1. Sasmaz, A.; Yaman, M.; Soil Sci. Plan. Anal. 2006, 37, 1845.

2. Soylak, M.; Elci, L.; Dogan, M.; Anal. Lett. 1997, 30, 623.

3. Soylak, M.; Elci, L.; Narin, I.; Dogan, M.; Trace Elem. Eletroly. 2001, $18,26$.

4. Mckenzie, H. A.; Smythe, L. E.; Quantitative Trace Analysis of Biological Materials, Elsevier: Amsterdam, 1988.

5. Baird, C.; Environmental Chemistry, $2^{\text {nd }}$ ed., Freeman and Longman: UK, 1999.

6. Narin, I.; Soylak, M.; Talanta 2003, 60, 215.

7. Dadfarnia, S.; McLeod, C. W.; Appl. Spectrosc. 1994, 48, 1331.

8. Rao, T. P.; Metilda, P.; Gladis, J. M.; Crit. Rev. Anal. Chem. 2005, 35, 247.

9. Oliva, A.; Molinari, A.; Zuniga, F.; Ponce, P.; Microchim. Acta 2002, 140, 201.
10. Hejazi, L.; Mohammadi, D. E.; Yamini, Y.; Brereton, R. G.; Talanta 2004, 62, 183

11. Rekha, D.; Suvardhan, K.; Dilip Kumar, J.; Subramanyam, P.; Reddy Prasad, P.; Lingappa, Y.; Chiranjeevi, P.; J. Hazard. Mater. 2007, 146, 131.

12. Ghaedi, M.; Ahmadi, F.; Shokrollahi, A.; J. Hazard. Mater. 2007, 142 , 272.

13. Abulhassani, J.; Manzoori, J. L.; Amjadi, M.; J. Hazard. Mater. 2010, $176,481$.

14. Shirani Bidabadi, M.; Dadfarnia, S.; Haji Shabani, A. M.; J. Hazard. Mater. 2009, 166, 291.

15. Afzali, D.; Ghazizadeh, A.; Salari, H.; Quim. Nova 2011, 34, 1124.

16. Mohammadi, S. Z.; Baghelani, Y. M.; Mansori, F.; Shamspur, T.; Afzali, D.; Quim. Nova 2012, 35, 198.

17. Dadfarnia, S.; Haji Shabani, A. M.; Anal. Chim. Acta 2010, 658, 107.

18. Jeannot, M. A.; Cantwell, F. F.; Anal. Chem. 1996, 68, 2236.

19. He, Y.; Lee, H. K.; Anal. Chem. 1997, 69, 4634.

20. Pereira, F. P.; Lavilla, I.; Bendicho, C.; Spectrochim. Acta, Part B 2009, 64, 1.

21. Asadollahi, T.; Dadfarnia, S.; Haji Shabani, A. M.; Talanta 2010, 82, 208.

22. Leong, M. I.; Huang, Sh. Da.; J. Chromatogr., A 2008, 1211, 8.

23. Xu, H.; Ding, Z. Q.; Lv, L. L.; Song, D. D.; Feng, Y. Q.; Anal. Chim. Acta 2009, 636, 28. 
24. Yamini, Y.; Rezaee, M.; Khanchi, A.; Faraji, M.; Saleh, A., J. Chromatogr., A 2010, 1217, 2358.

25. Rohani Moghadam, M.; Haji Shabani, A. M.; Dadfarnia, S.; J. Hazard. Mater 2011, 197, 176.

26. Xia, L.; Hu, B.; Jiang Z.; Wu Y.; Liang, Y.; Anal. Chem. 2004, 76, 2910.

27. Xia, L.; Wu, Y.; Hu, B.; J. Mass Spectrom. 2007, 42, 803.

28. Frajzadeh, M. A.; Venkateswarana, P.; Seal, L.; J. Ind. Eng. Chem. 2007, 14,110 .
29. Xia, L.; Hi, X.; Wu Y.; Hu, B.; Chen, R.; Spectrochim. Acta, Part B 2008, $63,1290$.

30. Sun, Zh.; Liang, P.; Ding, Q.; Cao, J.; J. Hazard. Mater. 2006, 137, 943.

31. Meeravali, N. N.; Reddy, M. A.; Kumar, S. J.; Anal. Sci. 2007, 23, 351.

32. Jiang, H.; Qin, Y.; Hu, B.; Talanta 2008, 74, 1160. 